\title{
Positioning of the US President in the World Political Process: To the Question of Defining the Research Methodology
}

\author{
Ekaterina Shevchenko ${ }^{1},{ }^{*}$ Mikhail Burda ${ }^{1}$, Olga Nesterchuk ${ }^{1,2}$, Sergey Popov ${ }^{2}$, Anna \\ Krivova $^{3}$
}

${ }^{1}$ Russian Presidential Academy of National Economy and Public Administration, Russia

${ }^{2}$ Peoples' Friendship University of Russia, Russia

${ }^{3}$ Russian State Social University, Russia

*Email: katerina.shevv@yandex.ru

\begin{abstract}
The current state of political science as a science of adjusting and diversifying the theoretical and methodological basis is characterized by some domestic and foreign researchers and experts as a crisis and (or) uncertain. This is due to the updating of the request regarding reproduction mechanisms formulation and scientific knowledge verification, which are adequate to the existing political trends (developing extremely dynamically and substantively). In turn, this explains the timeliness and targeted clarification of the adopted methods of political science research. In this sense, the problematic nature of determining a suitable research methodology is associated, firstly, with the borrowing of most of the theoretical positions and methodological attitudes from related disciplines (mainly from philosophy and sociology), and secondly, with the continuity of development (change) of the object under study, while not excludes indeterminism and inversion of modern science as such. The plane of political risks and opportunities of the modern world order raises the question of determining the adaptive and applied features of political science methodology in the context of fragmentation and co-evolution of the modern scientific picture of the world into a different quality of understanding and argument. Based on the understanding of the need to formulate a methodological toolkit for researching the positioning of the US president in the global political process, the authors determine the appropriateness of using the following methodological practices and approaches: conceptual formalization, comparative historical analysis, comparative political science analysis, multivariate analysis, narrative analysis, political discourse analysis, conceptual analysis, system analysis, problem-chronological analysis, statistical presentation of data. Also convincing is the use of a multiparadigm approach and an appeal to such areas as political elitology, political communication studies, political realism and political pragmatism, institutionalism and neo-institutionalism.
\end{abstract}

Keywords: Positioning, World political process, USA, US president.

\section{INTRODUCTION}

Political science at the current stage of development is faced with several objectively determined problems, which are predominantly structuralist and methodological in nature, associated with the need to concretize the position and functionality of political science in the spectrum of dynamically developing areas of modern scientific, humanitarian knowledge and updating the methods and tools used by this discipline. The political science subject field is expanding unprecedentedly, which reveals the ineffectiveness and irrelevance of most of the existing scientific research principles and practices. The process of formation of scientific, political knowledge is characterized by variability and mobility, which, however, does not eliminate the problem of preserving scientific dogmatism 
in its worst manifestation [1, p. 25]. In this sense, issues of world politics and international relations are no exception, where the comprehension of the categories of equilibrium and disequilibrium, permanence and discreteness, integrative and polarity, universalism and pluralism is characterized by a greater degree of complexity and dynamism. Thus, the need for methodological reflection on the problems of researching the positioning of the US President in the framework of the world political process seems to be very urgent.

\section{METHODOLOGY}

This study provides a rationale for the specifics of the applicability of both classical and generally accepted, as well as combined and synthesized methods (especially in the context of a large-scale statement of the promise of interdisciplinary research), which is achieved by turning to methods such as content analysis, the method of grouping and generalizing the material.

\section{RESULTS AND DISCUSSION}

The specificity of the subject of this research, which includes such properties as polyaspectal and multifactorial, actualizes, among other things, the need to search for adequate correlations and integrative elements of the theoretical and methodological foundations of American political science and Russian political science. As per O.V. Gaman-Golutvina opinion, additional complexity is the consideration and assessment of content-dynamic, anthropological, value, normative and other methodological (philosophical and methodological) components [2, p.28]. Nevertheless, within the framework of the study of the positioning of the US president in the global political process, it seems appropriate to use the following, in a certain sense, "traditional" methodological practices and approaches that fit optimally into the conceptual and discourse perspectives of the post-non-classical picture of the political world (without dwelling in detail on the presentation, in particular, historical and sociocultural contexts, allowing to make a more or less holistic conclusion regarding the epistemological and heuristic potentials of the methodology of modern political science):

- conceptual formalization interpreted as a kind of "starting point" and presupposing the identification of a conceptual-categorical apparatus that is most acceptable and fits in the best way with the general research focus and topic, which, accordingly, means the system of concepts and categories used, based on familiarization with existing scientific - research positions and scientific definitions. At the semantic (conceptual) level, such definitions as "positioning" and "world political process" are subject to serious elaboration. Also, the conceptualization of contiguous and auxiliary concepts and categories is not excluded, which is a semantic and interpretive basis, which in the future it is logical to use to operationalize and check the obtained material. Operationalization of the concepts and categories used is an integral task of any political science research $[3, \mathrm{p}$. 13];

- a comparative historical analysis that allows for a relatively holistic and comprehensive formation of an idea about the dynamics of changes in the indicators of the positioning of the US president in the world political process, constructed differently in a given period of the political history of the United States, appealing to the specifics of the American historical retrospective and the interpretation of the problems of the development of world politics. In particular, comparative historical analysis is used, among other things, in the study of the US migration policy, which is very controversial in the context of the formulation of an urgent political agenda in some works, an emphasis is placed on considering various practices of managing migration processes in the United States based on specific historical conditions and dynamic changes in the structural and institutional features of social relations [4];

- comparative political analysis, based, first, on the use of the conceptual and categorical apparatus of political comparative studies, and second, on the understanding of the correlation of the analyzed political phenomena and processes. In principle, it makes possible a more or less complete reflection of American political reality based on comparing the specific properties and characteristics of the political activity of the US president in the context of the world political process. It is reasonable to pay attention to high-quality techniques involving consideration of the aggregate indicators of the object under study [5, p. 126]. That means the prospect of excluding the possibility of reduction and incorrect interpretation of parameters is created;

- multivariate analysis, which is a "working" scheme for researching what, how, under what circumstances and with what effect it affects the production of meanings and activity aspects of the positioning of the US president in the global political process. A serious research task is to identify the links between these indicators and their extrapolation concerning the formulation of the desired results. That means the use of multivariate analysis adequately fits into the program of modern political science research, orienting the author to take into account several relatively recent political meanings and meanings characteristic of postmodernism and informational globalism, which are characterized by multimodality and extreme ambiguity;

- narrative analysis, the main methodological setting of which can be formulated based on the thesis regarding the narrativization of the surrounding reality by a political subject. Thus, the methodological value of narrative analysis lies in the definition of the basic 
(central) meanings and concepts that determine the political activity of the US President in the framework of the global political process. Properties such as reliability (objectivity), causality (cause-and-effect relationship), significance for an activity subject, and attractiveness for the target audience are also important. Narrative analysis is trendy not only among the American political science community but also among European political scientists who consider this issue in the context of the activity of right-wing populist political parties interested in depoliticizing some political stories and images that are important for the public to strengthen their own political ambitions, with an emphasis on such features like multilevel interpretation and complexity of contextuality [6];

- political discourse analysis, based, in particular, on descriptive and cognitive approaches, which implies minimizing the effect of any subjectivist provisions and identifying the grounds for ensuring stability (sustainability) of political activity. At the same time, the textual (political text, normative legal act) and contextual aspects (social level, political level) are investigated. In this regard, there is no need to delve into the political and psychological issues associated, in particular, with the study of the reproduction of forms of mass consciousness and framing, the stake is placed on the functional and instrumentalist aspects of the object under study. The implication is that through the use of political discourse analysis, it will be possible to recognize the key connecting elements between the foreign policy of the President of the United States and the world political situation;

- conceptual analysis that determines the specifics of the study of the positioning of the US president in the global political process based on the symbolic and symbolic nature of political communication (political interaction), one of the central characteristics of which is the recognition of the importance of some political images and the assertion of the failure of others. The conceptual analysis involves the study of concepts that build political reality based on a matrix of standards and rules adopted and approved by a specific political community;

- system analysis, which most successfully fits into the system of generally accepted views and positions regarding the essential features and development vector of current world political events. The interest in conducting a comprehensive political science study, one of the tasks of which is to consider the factors and conditions that affect the object itself, in their totality, determines the availability of understanding. In particular, the image and functional-activity features of the positioning of the US president in the global political process. In some works of American researchers, one can come across the operation of the definition of "consistency" in the context of expanding research boundaries concerning issues of world politics [7];

- problem-chronological analysis, focusing the attention of the researcher directly on the political role of the United States as a key political actor, influencing the choice of the trajectory of the development of the world political process and offering its version of decisionmaking at this level. A distinctive feature of the problemchronological analysis is to provide an opportunity to consider an object in a clearly defined time sequence, as well as taking into account the evolutionary and dynamic nature of its development, which presupposes the formation of a more or less objectified understanding of the positions of the US President, taking into account the problems of world politics;

- data statistical presentation implying a quantitative expression of the manifestation of political activity by the President of the United States in the issue of positioning in the global political process. In particular, that means the study of issues such as participation in the activities of specific international organizations and interstate associations (institutional aspect) and the adoption of those that are important for the majority representatives of the international decision-making community (functional aspect).

Thus, in a generalized version, these methodological practices and approaches can be presented as follows:

- conceptual formalization;

- comparative historical analysis;

- comparative political analysis;

- multivariate analysis;

- narrative analysis;

- political discourse analysis;

- conceptual analysis;

- system analysis;

- problem-chronological analysis;

- data statistical presentation.

Within the author's political science research, which has scientific novelty and applied value, depending on the target attitudes and the object-subject field, it will be sufficient to turn to some particular research tools and techniques within such areas as political elitology, political communication studies, political realism and political pragmatism, institutionalism and neoinstitutionalism.

The indicated methodological foundations of the study of the positioning of the US president in the world political process, nevertheless, do not limit the research search for other methodological possibilities and do not exclude the placement of emphasis based on the 
recognition of the effectiveness of using the multiparadigm approach based on the symbiotic nature of the approved methodological practices. According to K. Ardalan, the use of a multi-paradigm approach is advisable, in principle, within the framework of humanitarian research in terms of providing a more balanced understanding of the object under study [8]. In this regard, we can focus on the synthesis of theoretical speculations and empirical data in the spirit of the implementation of the poly-narrative model [9, p.186]. This is also reflected in the thesis on the effectiveness of the appeal to methodological pluralism [10, p.171].

\section{CONCLUSIONS}

The presentation of these methodological practices and approaches recommended for use in the study of the positioning of the US president in the world political process is based on the systematization and criteria-based selection of generally approved and specific research methods adopted and used by domestic and foreign scientific schools in the context of studying political phenomena and processes.

Considering a detailed study of the features and results of some modern political science studies, the prospects for using the following methodological spectrum were determined: conceptual formalization, comparative historical analysis, comparative political science analysis, multivariate analysis, narrative analysis, political discourse analysis, conceptual analysis, system analysis, problem chronological analysis, statistical presentation of data.

This will allow, on the one hand, to determine epistemological trends in the direction of researching the position of the US president in the global political process and to consider the object under study comprehensively. On the other hand, considering the methodological tools used, to concretize research opportunities and to formulate criteria for the approbation of the results obtained.

\section{ACKNOWLEDGMENTS}

This article has been supported by the RUDN University Strategic Academic Leadership Program

\section{REFERENCES}

[1] T.A. Alekseeva, A.P. Mineev, Naturalism and Political Science: Adaptation to a Non-Classical World view, Law and Governance 21 Century Vol. 16 Iss. 1(54) (2020) 14-27. DOI: https://doi.org/10.24833/2073-8420-2020-1-54-14$\underline{27}$

[2] O.V. Gaman-Golutvina, Overcoming Methodological Differences: The Controversy
About Politics In An Age Of Uncertainty, Polis, Political Studies 5 (2019) 19-42. DOI: https://doi.org/10.17976/jpps/2019.05.03

[3] Yu.V. Irkhin, Modern methodological, theoretical and methodic approaches to political analysis, Questions of political science 1(21) (2016) 7-17. DOI: Not Available

[4] J. Jiang, The Politics Of Punishment and Protection: A Comparative Historical Analysis Of American Immigration Control, Law \& Policy, 1990-2017 Vol. 42 Iss. 2 (2020) 125-161. DOI: https://doi.org/10.1111/lapo.12146

[5] L.V. Smorgunov, Ontological turns in modern political science: in search of adequacy to politics, Social and Humanitarian Knowledge Vol. 6 Iss. 2 (2020) 122-133. DOI: http://dx.doi.org/10.18255/2412-6519-2020-2-122$\underline{133}$

[6] K. Freistein, F. Gadinger, Populist Stories of Honest Men and Proud Mothers: A Visual Narrative Analysis, Review of International Studies Vol. 46 Iss. 2 (2020) 217-236. DOI: https://doi.org/10.1017/S0260210519000421

[7] C. James, P. James, Systemism and Foreign Policy Analysis: A New Approach to The Study of International Conflict, Advancing Interdisciplinary Approaches to International Relations, Palgrave Macmillan, 2017, 344 p. DOI: https://doi.org/10.1007/978-3-319-40823-1_10

[8] K. Ardalan, Ideology: A Multi-Paradigmatic Approach, Journal of Interdisciplinary Economics Vol. 31 Iss. 2 (2019) 124-142. DOI: https://doi.org/10.1177/0260107917736408

[9] G.L. Tulchinsky, Three Narratives of Political Science: Prospects for the Interdisciplinarity of Political Research, Political Expertise: POLITEX, Vol. 15 Iss. 2 (2019) 20-46. DOI: https://doi.org/10.21638/11701/spbu23.2019.202

[10] V.I. Burenko, On the beginning and origins of modern Russian political science (30 years of Russian political science), PolitBook 3 (2019) 164179. DOI: Not Available. 